\section{A MODEL COMMUNITY}

This issue is almost entirely dedicated to models and modeling, a set of topics marked by dramatic change in the last couple of decades. There was a time in the history of oceanography when modelers were considered something of a caste unto themselves, comprised of the cyber-centrics with a propensity for seasickness. Back in the 1970s and early 1980s oceanographic models were viewed as a quirky means of extrapolating sparse data into meaningful hypotheses. Most models were cranked out on paper-tape-consuming prehistoric machines like the old PDP-11s. The output-usually an array of digits and number patterns requiring secondary and tertiary interpretations before their significance could be gleaned-although archaic, showed signs of the potential for modeling in terms of planning experiments, or assessing coarse oceanographic features (e.g. basin-scale gyres, and interannual trends). By the late 1980 s a transformation began occurring. Model output was enhanced by more sophisticated graphical user interfaces, making the forecasting and nowcasting effectiveness of models even more evident. New applications of non-linear dynamics added levels of sophistication to the models, so that they were applicable to a much broader (and higher resolution) set of scales in space and time. And computational power meant that machines could handle parallel processing at rates of trillions or even quadrillions of operations per second. This meant that those historically 'intractable' oceanographic problems (e.g. airsea coupling, turbulence, climate scale phenomena) might be addressable with the next generation of models. Within the last decade we've started down some new paths. Model output is referred to as 'data', inseparable from, integrated with, and assimilated into those parameters that are sensed and observed. More significant, perhaps, is the fact that models are now a tool of choice in a range of operational applications. Most First World navies use ocean models to support safe transits of their fleets. The reinsurance industry relies heavily on deterministic models to minimize the risk of their geographically distributed investments. And now we are seeing a growing number of resource managers who are integrating modeling efforts with their traditional monitoring programs, to ensure sustainability of a wide array of living and non-living marine resources.

As you read the articles in this issue keep thinking about where these capabilities are going, and where we will be in ten years. What will be the role of the seagoing oceanographic community, with respect to models? How will we-in the oceanographic community - take best advantage of the continued rapid growth in the information technology? What new theoretical concepts will we be best able to exploit with our models? In the meantime, you can probably throw away those old rolls of paper tape!

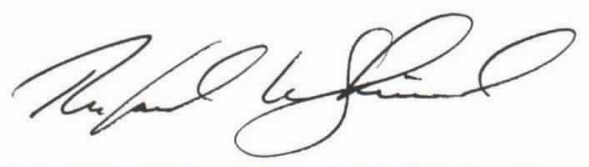

OCEANOGRAPHY

www.tos.org

EDITOR

Richard W. Spinrad

U.S. Naval Observatory

3450 Massachusetts Avenue, NW

Washington, DC 20392-5421 USA

(202) 762-1697 Fax: (202) 762-1025

spinrad.richard@hq.navy.mil

\section{ASSISTANT EDITOR}

Elizabeth J. Tirpak

magazine@tos.org

\section{ASSOCIATE EDITORS}

Gregg J. Brunskill

Australian Institute of Marine Science PMB No. 3, Townsville, M.C. Queensland 4810, Australia

(61) 747534481 Fax: (61) 747725852 g.brunskill@aims.gov.au

Ellen R.M. Druffel

Department of Earth System Science

222 Roland Hall University of California Irvine, California 92697-3100 USA

(949) 824-2116 Fax: (949) 824-3256 edruffel@uci.edu

Charles H. Greene

Director, Ocean Resources and Ecosystems Program Department of Earth \& Atmospheric Sciences Cornell University 2130 Snee Hall

Ithaca, New York 14853-2701

(607) 255-5449 Fax: (607) 254-4780 chg2@cornell.edu

James Syvitski

Director, Institute of Arctic and Alpine Research University of Colorado at Boulder 1560 30th Street, Campus Box 450 Boulder, Colorado 80309-4050 USA (303) 492-7909 Fax (303) 492-6388 james.syvitski@colorado.edu

Peter Wadhams

Scott Polar Research Institute

University of Cambridge Lensfield Road

Cambridge CB2 1ER England

+44 1223-336542

pw11@phx.cam.ac.uk

\section{DESIGN/PRINTING}

Corporate Press

403 Brightseat Road

Landover, Maryland 20785 USA 